\title{
Chitosan suppresses the expression level of WRKY17 on red chili (Capsicum annuum) plant under drought stress
}

\author{
Muhammad Abdul Azizi, ${ }^{1,3}$, Rizkita Rachmi Esyanti ${ }^{1, *}$, Karlia Meitha ${ }^{1,2}$, Fenny Martha Dwivany ${ }^{1,2}$, and Hany Husnul \\ Chotimah $^{1}$ \\ ${ }^{1}$ School of Life Sciences and Technology, Institut Teknologi Bandung, West Java, Indonesia \\ ${ }^{2}$ Research Center for Nanosciences and Nanotechnology, Institut Teknologi Bandung, West Java, Indonesia \\ ${ }^{3}$ Indonesian Research Institute For Biotechnology and Bioindustry, Jl. Taman Kencana No. 1 Bogor, West Java, Indonesia 16128 \\ *Corresponding author: rizkita@sith.itb.ac.id
}

SUBMITTED 23 March 2020 REVISED 5 May 2020 ACCEPTED 22 May 2020

\begin{abstract}
Chili pepper plays a significant role in the global market. However, the production is often impeded by drought stress involving WRKY genes as the defense regulator. Chitosan is considered as a promising alternative fertilizer and defense elicitor. Hence, this study aimed to determine the role of chitosan in improving plant growth and survival of red chili pepper against drought stress. At the onset of the generative phase, chili plants were subjected to $1 \mathrm{mg} / \mathrm{mL}$ chitosan, $50 \%$ drought, or chitosan-drought treatment. Observations were made on several growth parameters, opened stomata, and WRKY gene expression. The results showed that chitosan-drought treatment decreased plant growth and yielded significantly. The percentage of opened stomata was recorded at 0.56 -fold lower than control. It was followed by the decrease of the relative expression of WRKY17 and WRKY53 genes up to 0.56 and 0.72 -fold lower than control, respectively. Therefore, we suggested that the double treatment of chitosan-drought might decrease plant growth performance but increase the defense system by suppressing the expression level of the WRKY17 gene. Interestingly, the drought treatment significantly increased WRKY17 expression level up to 7-fold higher than control. Hence, it was suggested that WRKY17 has a specific role in response to drought stress.
\end{abstract}

KEYWORDS red chili; chitosan; drought; growth performance; gene expression

\section{Introduction}

Red chili pepper (Capsicum annuum) is a widely domesticated and very popular plant throughout the world, routinely consumed by about one-fourth of the global population (Khan et al. 2014). In Indonesia, this plant is one of the most prioritized vegetables with a high economic value used for daily consumption, food industries, and export commodities. In 2014, the total production was about 1.075 million tons or around $9.02 \%$ of Indonesia's national vegetable production (KEMENTAN 2015). The average demand for this commodity in the urban area is around 66,000 tons per month increasing up to $20 \%$ at a certain period. However, red chili production in Indonesia fluctuates from time to time and is often unable to meet the market needs. In addition to pathogen infection, the decrease of production is also caused by limited hydration. For instance, the phenomenon of drought in the Semarang district caused $500 \mathrm{Ha}$ of agricultural land to be affected, and 72 hectares experienced crop failure in 2014 (KEMENTAN 2016). If this phenomenon occurs in a prolonged period, it might inhibit plant growth or death, resulting in low productivity, increased prices, and decreased export commodities.

Drought is the most frequent abiotic stress experienced by plants due to global climate change in recent years (Khan et al. 2014). In general, the plant will respond to water stress by synthesizing abscisic acid (ABA) as the defense regulator, which leads to closed stomata. It aims to reduce the rate of transpiration, but it also impacts decreasing photosynthesis rate, resulting in decreased plant growth and productivity (Iriti et al. 2009). Under stress conditions, a plant can carry out the various defense mechanisms through molecular, cellular, and biochemical integration (Khan et al. 2014). WRKY is a transcription factor known to play a role in the abscisic acid (ABA) and jasmonic acid (JA) signaling pathways in response to drought stress. WRKY is characterized by the existence of one or two conserved WRKY domains in the N-terminus and a zinc finger motif in the C-terminus. These two elements are crucial for the affinity of WRKY protein binding with the consensus sequence $(\mathrm{C} / \mathrm{T}) \mathrm{TGAC}(\mathrm{C} / \mathrm{T})$ called W-box. There are 74 kinds of WRKY protein found in Arabidopsis and classified into three groups based on the number and 
type of WRKY domain. Group III, such as WRKY46 and 53, was characterized by one $\mathrm{C}-\mathrm{C}-\mathrm{H}-\mathrm{C}$ zinc finger, group II (for example, WRKY11, 15, 17, and 39) by one C-C-H$\mathrm{H}$ zinc finger, while group I by two C-C-H-H zinc finger (Yan et al. 2014). The previous study reported that the alteration of WRKY genes expression level was in line with plant defense regulation under stress (Yan et al. 2014; Sun and Yu 2015).

The improvement of plant growth and resistance using environmentally friendly technologies is continuously developed since the excessive use of chemical substances is often destructive such as the accumulation of pesticide residues, pathogen resistance, eradication of natural predators, and environmental pollution (Duriat et al. 2007). Chitosan is one of the most promising candidates of natural fertilizer that is widely studied due to its various characteristics such as environmentally friendly, edible, having antifungal and anti-transpirant activity, and also can boost plant defense system. The application of foliar chitosan spraying on coffee increased chlorophyll and carotenoid content of leaves around 46.38 to $73.51 \%$, mineral absorption which includes $9.49 \% \mathrm{~N}, 11.76 \% \mathrm{P}, 18.75 \% \mathrm{Mg}$, and $3.77 \% \mathrm{Ca}$ and plant height up to $33.51 \%$, and also increased resistance to drought (Dzung et al. 2011). In addition, the application of 100 and 125 ppm chitosan was proven to increase the growth and productivity of okra (Mondal et al. 2013). The previous study demonstrated that the anti-transpirant activity of chitosan was related to the synthesis of ABA as a regulator of resistance mechanisms by inducing closed stomata (Iriti et al. 2009). Thus, chitosan is coincided as the potential agent to promote plant growth and survival under drought conditions.

However, the role of chitosan on physiological and molecular mechanisms during drought stress has not been studied thoroughly, particularly in the plant defense mechanisms. Thus, in this study, we used red chili pepper LADO cultivar, which was given a combination of $1 \mathrm{mg} / \mathrm{mL}$ chitosan and 50\% of drought treatment to determine the plant physiological (growth performance and stomatal behavior) and molecular (WRKY genes expression) responses. This study aimed to determine the role of chitosan in improving plant growth and survival of red chili pepper against drought stress.

\section{Materials and Methods}

\subsection{Plants Materials and Treatments}

The cultivation and treatments of red chili pepper (C. annuum) cultivar LADO (East-West Seed Indonesia Ltd.) was conducted at the greenhouse at Institut Teknologi Bandung, Indonesia. This experiment was conducted for \pm $112 \mathrm{~d}$ with the average of photoperiod was $12 \mathrm{~h}$, relative humidity of $78.96 \%$, a light intensity of 10240 lux, and at temperature $\pm 27.78^{\circ} \mathrm{C}$ (Supplementary 1 ). Individual red chili pepper was grown in a plastic polybag with $3 \mathrm{~kg}$ planting medium containing soil, husks, and organic fertilizer (4: 3: 2). The plantlets were watered up to $100 \%$ field water capacity as long as 7 of the weeks. At the onset of generative phase, as indicated by the emergence of flower buds, the plantlets were subjected to the treatments of chitosan (Chi), chitosan \& drought (Chi-D), drought (D), and control (C) up to sixteenth weeks of planting ( $\mathrm{n}=3$ biological replications of each treatment).

Chitosan solution was prepared as described in Esyanti et al. (2019) by diluting chitosan powder into a glacial acetic acid solution $(0,07 \%)$ to a concentration of $1 \mathrm{mg} / \mathrm{mL}$ and sprayed weekly by foliar feeding technique to Chi and Chi-D treatments. It suggested that the $1 \mathrm{mg} / \mathrm{mL}$ chitosan solution was able to maintain the cultivar's growth rate (Esyanti et al. 2019). Drought treatment was applied to reach $50 \%$ of field water capacity by using $500 \mathrm{~mL}$ of water in $2 \mathrm{~d}$ subjected to $\mathrm{D}$ and Chi-D treatments. It suggested that $50 \%$ of deficit irrigation is a feasible irrigation strategy to maintain plant growth performance (Dorji et al. 2005). Also, the control group (C) was watered by $100 \%$ field water capacity but not sprayed with any solutions. Fresh leaves from 3 plants were collected at 50 - $60 \mathrm{~d}$ after flowering (harvesting period) (Sung et al. 2005) into one sample and used for RNA extraction to analyze WRKY genes expression level $(n=3$ technical replications of each treatment).

\subsection{Measurement of Physiological Parameters}

The physiological parameters, including plant height, the number of leaves, flowers, and fruits were recorded weekly starting from week 8 to 16 . Plant height was measured using a ruler, determining the length of the main stem from the base line up to the tip, while the firmly attached organs, including leaf, flower, and fruit, were handcounted. It determines the remaining plant organ number from abscission, fallen organs. Stomatal behavior was evaluated by making the mold on the lower part of chili leaves during the day and then observed under a light microscope (NIKON, SM2445). Furthermore, the percentage of the opened stomata was calculated using the corresponding method described by Fibriyanti (2008).

\subsection{RNA Extraction and qPCR Analysis}

The total RNA was extracted from the frozen pepper leaves (50 mg) using the PureLinkTM RNA mini kit (Invitrogen). The quality of RNA was evaluated in a $1.5 \%$ $(\mathrm{w} / \mathrm{v})$ agarose gel with gel red as a coloring agent using an electrophoresis instrument. Meanwhile, the quantity of RNA was evaluated using a nanodrop spectrophotometer (Eppendorf, biospectrometer) to know the purity of RNA and also to quantify RNA concentration. DNAse treatment was performed using DNAseI (Thermo Scientific), while cDNA synthesis was carried out using iScript cDNA Synthesis Kit (Bio-Rad) containing reverse transcriptase enzyme. The quality of cDNA was determined in a $2 \%$ agarose using CaUbi3 as the housekeeping gene with the specific primer, as explained in Table 1. The Polymerase Chain Reaction (thermal cycler) condition was performed as follow: $95{ }^{\circ} \mathrm{C} 3 \mathrm{~min}, 95^{\circ} \mathrm{C} 30 \mathrm{~s}, 58^{\circ} \mathrm{C} 30 \mathrm{~s}, 72{ }^{\circ} \mathrm{C}$ $1 \mathrm{~min}, 72^{\circ} \mathrm{C} 5 \mathrm{~min}$ (35 cycles). The experiment was re- 
TABLE 1 Primer for WRKY and CaUbi3 genes.

\begin{tabular}{llll}
\hline Primer & Accession number & Nucleotide (5' to $\mathbf{3}^{\prime}$ ) & Size (bp) \\
\hline WRKY17 & XM_016699929.1 & & 181 \\
Forward & & GGGGTTACTACAGATGCAGC & \\
Reverse & CTCTGGCCAGAACTTCCATC & 192 \\
WRKY53 & NM_001324692.1 & & 201 \\
Forward & & ACAGATGCACGTATCGTCAC \\
Reverse & GCCTGTTTTGATAAACGGCC & \\
CaUbi3 & & & \\
Forward & AY486137.1 & TCCATCTGCTCTCTGTTGACG & \\
Reverse & & CCCCAAGCACAATAAGACATTGT & \\
\hline
\end{tabular}

peated three times ( $\mathrm{n}=3$ technical replications).

Amplification of WRKY genes was performed by using specific primers, as mentioned in Table 1 . After confirmed by using agarose electrophoreses, sequencing was performed through the Macrogen service, Korea. And then, the quantitative PCR was performed by using instruments and software from MyGo Pro with the dye from Toyobo (Thunderbirds Sybr qPCR Mix QPS-201). The quantification cycle (Cq) score was then used for quantifying the expression level through a relative method by using the corresponding formula, as described by Livak and Schmittgen (2001).

\subsection{Statistical analysis}

The significant differences among the treatments were determined using the Tukey HSD test at $P<0.05$ using $\mathrm{R}$ studio 3.5.2 (32/64 bit) application. The principal component-biplot analysis (PCA), the heatmap clustering analysis (HCA), and the correlation analysis were performed using the MetaboAnalysed 4.0 application. Those analyses were performed to cluster among the treatments and also to determine the correlation among the parameters. In addition, the effect of chitosan, drought, and the interaction of both treatments towards the increase in height, the percentage of opened stomata, and WRKY genes expression level were analyzed by Two-way ANOVA performed using IBM SPSS statistics 22 software.

\section{Results and Discussion}

\subsection{Chitosan Application under Drought Stress De- creased Plants Growth Performance}

The effect of chitosan application and/or drought treatment to red chili pepper on growth performance parameters including height increment, the number of leaves, flowers, and fruits in the generative phase was indicated in Figure 1. The initial plant growth condition at the vegetative phase was determined at the similar performance indicated by the similar growth parameters at week 8 for the number of leaves and flower and also at week 10 for the number of fruits. According to the investigation, the minimum height increment was recorded on the double treatment of chitosan and drought (Chi-D) at $30.67 \mathrm{~cm}$. The maximum increase in height was showed by Chi treatment at 49.67 $\mathrm{cm}$, whereas that of D and C treatments was at $44 \mathrm{~cm}$ and $47.67 \mathrm{~cm}$, respectively. In addition, the drought treatment showed an average decrease of $\pm 5 \mathrm{~cm}$ in plants compared to the control.

The effect of chitosan application during drought stress condition was also determined based on the number of leaves from week 8 to 16 . Overall, plants under Chi-D treatment possessed the minimum number of leaves, with a total of 114 in week 16 (Figure 1B). Chi treatment showed the maximum number of leaves in weeks 9 and 10 . In general, $\mathrm{D}$ and Chi-D treatments suppressed the number of leaves since week 10 when compared to that of $\mathrm{C}$ and Chi. Hence, the application of $1 \mathrm{mg} / \mathrm{mL}$ chitosan under $50 \%$ of drought stress condition inhibited growth in red chili pepper showed by the lowest height increment and leaves number.

The yield was evaluated as the number of flowers and fruits. The results showed that chitosan application during drought conditions (Chi-D) resulted in the minimum total number of flowers. The maximum number of flowers was observed in week 11 on the control group (Figure 1C). A steep decrease was detected after week 11 in all treatments that could occur due to the abscission and fruit development. An exponential fruit emergence was recorded in weeks 11 to 12 (Figure 1D) in almost all treatments. However, the immature fruits did not entirely reach the mature stage, with fruit abscised as early as in week 12 . Chi-D treatment was only able to produce the least number of ripe fruits. However, Chi-D treatment showed inferior values in almost all measured parameters of growth performance and yield.

\subsection{Chitosan Application During Drought Condition Promoted Stomatal Closure}

The closed stomata state of Chi-D treatment and the opened stomata of control are indicated in Figure 2A and B. Chitosan application under drought stress (ChiD) significantly decreased the number of opened stomata. The result showed that there was only a $30.67 \%$ of opened stomata in the Chi-D treatment, whereas that in $\mathrm{D}$ treatment was recorded at $32.44 \%$. Chitosan treatment also decreased the percentage of opened stomata by 

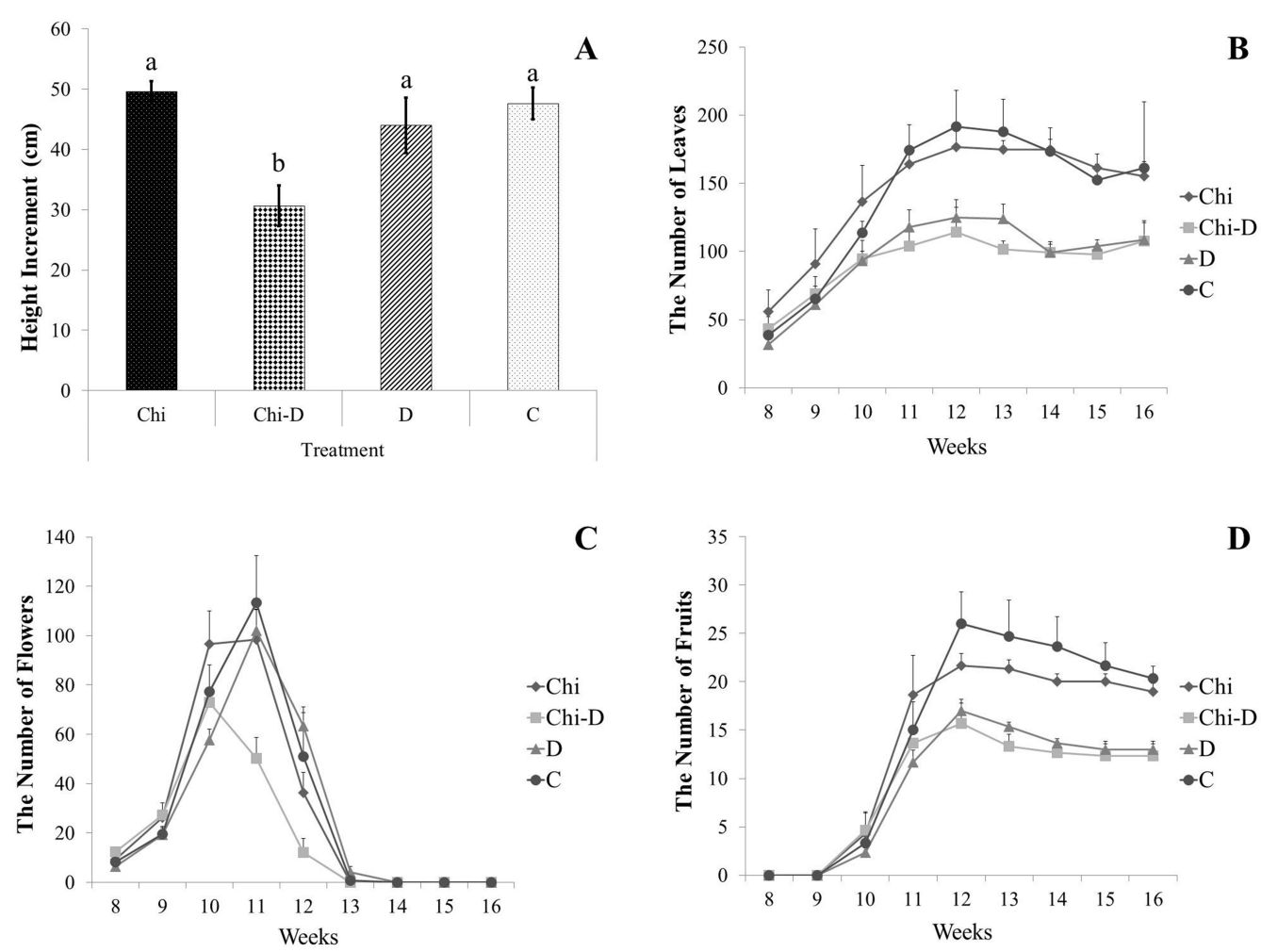

FIGURE 1 The growth performance of red chili pepper plants. (A) The height increment was calculated from the difference at the start (week 8) and end (week 16). The number of leaves (B), flowers (C), and fruits (D) were measured from the start (week 8) to the end (week 16) of each treatment. The bars represent the mean of each growth parameter with corresponding standard error $(n=3)$. A significant value is indicated by the letter on top of each bar, $(P<0.05)$. Chi, $1 \mathrm{mg} / \mathrm{mL}$ chitosan; Chi-D, $1 \mathrm{mg} / \mathrm{mL}$ chitosan and 50\% drought; D, 50\% drought; C, control.

42.75\%, while the highest of opened stomata, 54.97\%, was recorded in control (Figure 2C).

\subsection{Transcription Factor WRKY genes Regulated Growth and Defense Mechanism During Chitosan Application Under Drought Condition}

To conduct the relative gene expression analysis, the validation in every former step needs to be performed. Based on the total RNA visualization, there are two bands with the sizes of 28s and 18s (Supplementary 2) by means that the total RNA was successfully extracted. Spectrophotometry analysis showed that the purity of RNA (ratios $\lambda 260$ and $\lambda 280$ ) ranged from 2.12 to 2.14 , while the obtained concentrations ranged from 353.1 to $410.9 \mu \mathrm{g} / \mathrm{mL}$. Based on the sequencing result for a \pm 150 bp of the PCR product, after being analyzed using BLAST, a 100\% identity value was confirmed with the WRKY17 gene (accession number: XM_016699929.1) and WRKY53 gene (accession number: NM_001324692.1) (Supplementary 3). WRKY17 and WRKY53 were used to analyze the influence of chitosan on plant growth and defense response against drought stress.

In this study, we found that the relative expression level of WRKY17 and WRKY53 gene was significantly down-regulated in almost all treatments. The result showed that chitosan application under drought stress (Chi-D) decreased the relative expression level of
WRKY17 and WRKY53 up to 0.56 and 0.72-fold lower than control, respectively (Figure 3). Individual chitosan application (Chi) showed the relative expression level of WRKY17 and WRKY53 up to 0.67 and 0.47-fold lower than control, respectively. Interestingly, in addition to almost all genes expression level of WRKY were recorded lower in all treatments, the only expression level of WRKY17 in D treatment was up-regulated up to 7-fold higher than control. Different from WRKY17, the expression level of WRKY53 in D treatment was only 0.12-fold lower than control. We also found that chitosan application under drought stress resulted in the different responses between WRKY17 and WRKY53 gene expression.

\subsection{The Correlation of Physiological and Molecular Re- sponses after Coupled Treatment of Chitosan and Drought in Chili Plants}

Principal Component-biplot Analysis (PCA) was carried out to understand the grouping pattern of the measured parameter with the treatment groups. In Figure 4A, the PCA result showed a 91.005\% score of PC1 followed by an $8.816 \%$ of PC2. This indicates a classification pattern of the treatments defining that chitosan application under drought condition (Chi-D) is distinct from the drought treatment (D) group. In contrast chitosan treatment (Chi) and the normal condition (C) are classified into one group. The number of leaves indicates a powerful parameter clus- 

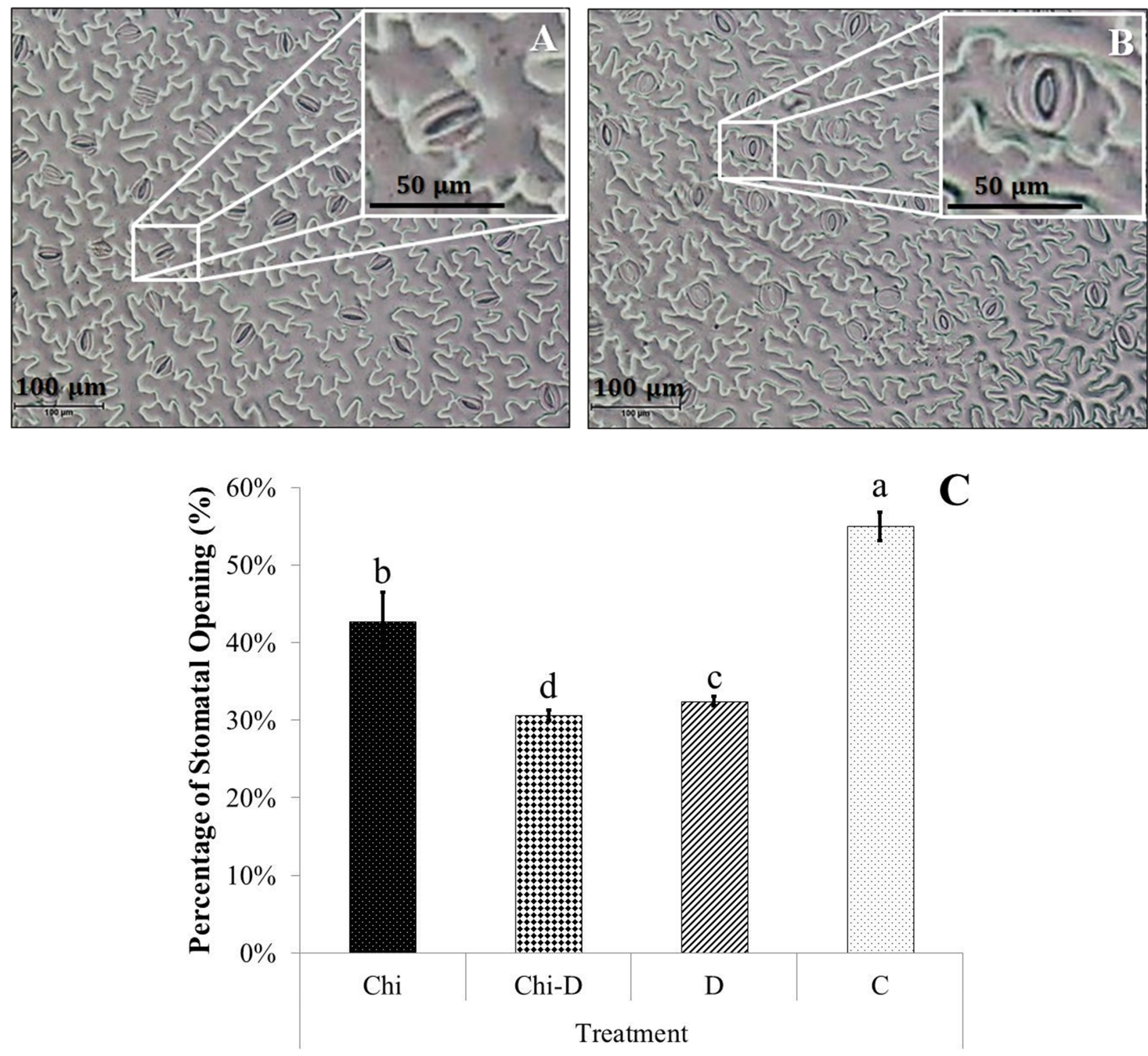

FIGURE 2 The stomatal behavior of chitosan-drought [Chi-D] treated plants (A) and control [C] (B) and the percentage of opened stomata (C) in red chili plants caused by chitosan application under drought stress condition. The bars represent the mean of the percentage of stomatal opening with the corresponding standard error $(n=3)$. Significant value is indicated by the letter on top of each bar, $(P<0.05)$. Chi, $1 \mathrm{mg} / \mathrm{mL}$ chitosan; Chi-D, $1 \mathrm{mg} / \mathrm{mL}$ chitosan and 50\% drought; D, 50\% drought; C, control.

tering Chi and $\mathrm{C}$ groups into the one quadrant, while the expression of the WRKY17 gene only separates the D group to the other quadrant.

Furthermore, to generate a deeper understanding of the correlation among parameters, the heatmap clustering analysis (HCA) was generated. The result (Figure 4B) showed that Chi and $\mathrm{C}$ groups are clustered together, as shown in the PCA score plot result. Interestingly, Chi$\mathrm{D}$ and $\mathrm{D}$ groups are in another cluster. The clustering among parameters, it is forms two major groups defining the WRKY17 gene as the out-group. In another group, there is a physiological parameter clustered in one group, while the WRKY53 as the other out-group. This is supported by the correlation analysis (Figure 4C) stated that almost all physiological parameters showed a strong positive correlation with each other $(r=0.61-0.89)$. However, the expression of the WRKY53 gene is positively correlated with the stomatal behavior $(r=0.64)$, contrasting the negative correlation $(r=-0.78)$ between WRKY17 and WRKY53.

\subsection{Discussion}

Most of the time, plants live in a habitat composed of a complex set of stresses. Understanding crop plant responses towards these stresses are fundamental to develop strategies that retain yield. Drought is considered as one of the most threatening conditions in the face of climate change, impeding the production of crop plants. Plant's response to drought is also complex, in which some are general across cultivars or even species, while others are distinctive in a certain genotype only. LADO is a commercial cultivar of red chili pepper (C. annuum) from EastWest Seed Ltd. LADO is widely cultivated due to its adaptive properties to a wide range of altitudes and the ability to produce 18-20 tons/Ha. It was shown that plants response to drought involves jasmonic acid (JA), but suppresses the activity of growth hormones such as gibberellic acid (GA). In this presented study, the low increase in height indicated a growth restraint during drought (Wasternack 2014). The similar results were showed that $50 \%$ of drought stresses 


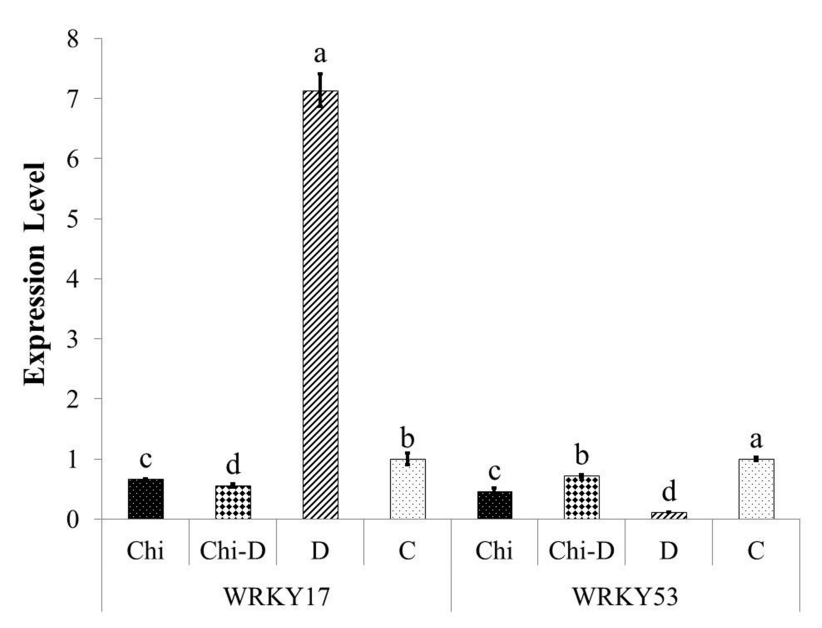

FIGURE 3 WRKY genes expression level of red chili plant treated by chitosan under drought stress condition. The bars represent the mean of WRKY genes expression level with the corresponding standard error $(n=3)$. Significant value is indicated by the letter on top of each bar, $(P<0,05)$. Chi, $1 \mathrm{mg} / \mathrm{mL}$ chitosan; Chi-D, $1 \mathrm{mg} / \mathrm{mL}$ chitosan and 50\% drought; D, 50\% drought; C, control.

decreased $13-15 \%$ of plant height (Him and Radhouane 2015), while a $34.7 \%$ decrease of fresh weight under the same stress was evaluated by Dorji et al. (2005).

The increase in the height of chitosan treatment (Chi) was more significant than control, suggesting this polymer capability to improve the plant's growth. The previous study showed that chitosan application under normal conditions by the foliar feeding technique resulted in an increase in the height of coffee plants up to $33.51 \%$ (Dzung et al. 2011). Besides, it was also demonstrated that chitosan application increased plants height significantly about $10 \mathrm{~cm}$ compared to the control accompanied by an increase in chlorophyll levels (Salachna and Zawadzińska 2014). These phenomena suggested due to chitosan that contains the abundance of amine (N) groups. Thus it was thought to play a role in plant growth, such as forming new cells and cell elongation (Ohta et al. 2004; Dzung et al. 2011). However, the double treatment of chitosan and drought (Chi-D) showed the lowest increase in height. This is following the assumption of Iriti et al. (2009) that the combination of chitosan application and drought in plants could cause a synergistic response in improving defense mechanisms but resulted in inhibited growth.

In each treatment, the number of leaves, flowers, and fruits peaked in weeks 11 and 12, followed by a steep decrease in week 13, which could occur due to the organ abscission. Further, the abscission of main organs such as leaves and flowers leads to a decline in plant growth and productivity (Sumarni and Muharam 2005). Naturally, abscission is also a strategy to face unfavorable environmental conditions. The previous study described that microclimate conditions such as temperature, humidity, and light intensity during cultivation highly influence the plant's growth (Taylor and Whitelaw 2001). We recorded the highest temperature in week 13, with an average of $31.48^{\circ} \mathrm{C}$, which was higher than the suggested temperature for chili plant cultivation at $25-27^{\circ} \mathrm{C}$ during the day and $18-20^{\circ} \mathrm{C}$ at night. Thus, this warmer microclimate might promote higher transpiration and reduce turgor in various organs that lead to abscission, as stated by Sumarni and Muharam (2005). Similarly, it was reported that drought stress in $C$. annuum decreased the number of leaves by $45 \%$, flowers by $79 \%$, and fruits by $88 \%$ (Showemimo and Olarewaju 2007).

The previous study suggested that the chitosan application was able to alleviate drought stress. It has been reported that the application of $0.4 \mathrm{~g} / \mathrm{L}$ chitosan improved the growth of Ocimum basilicum plants, either in drought treatment or control (Malekpoor et al. 2016). Interestingly, $1 \mathrm{mg} / \mathrm{mL}$ chitosan application and 50\% drought treatment combination (Chi-D) showed the most mediocre growth performances, as observed in the increase in height rate, the number of leaves, flowers, and fruits. However, in the previous study, chitosan was only applied three times during vegetative until generative phases. While in this study, chitosan was applied once a week (eight times) during the generative phase with a concentration of $1 \mathrm{mg} / \mathrm{mL}$, which is higher than the previous study. Thus, there was a different intensity and concentration of chitosan application, which thought to cause a different response in different species.

Under drought conditions, C3 plants such as chili pepper will respond to close stomata, so that the photosynthesis rate will decrease. The closure of stomata alters gas exchange in plants, which can induce organ abscission (Sumarni and Muharam 2005). The assumption of the negative effects of intensive chitosan application on growth performance was supported by stomatal behavior observation as displayed in Figure 2. Photosynthesis is the primary process of supplying energy for plant growth, while the alteration of stomatal movement might indirectly hinder growth progression. We found that the number of opened stomata decreased in all treatments compared to the control group. However, we recorded that the number of opened stomata in Chi-D plants was the least among all treatments. This suggested that both water deficit and elicitation from foliar application of chitosan were able to induce irregular stomatal state.

Furthermore, the previous study reported that chitosan application could reduce opened stomata by triggering reactive oxygen species (ROS) production such as $\mathrm{H}_{2} \mathrm{O}_{2}$. At the same time drought stress also leads to highly synthesized ABA, which also induces ROS production (Pichyangkura and Chadchawan 2015). ABA is highly synthesized when the plants experienced water deficiency, which will further induce the ROS production as the main signaling molecule. Following this, ROS will trigger nitric oxides (NO) production to inhibit membrane proton pump and the influx of $\mathrm{Ca}^{2+}$ between the plasma membrane and vacuole. Increased $\mathrm{Ca}^{2+}$ concentration causes anion efflux, so the membrane is depolarized, then the pressure of turgor and cell volume decreases, and the stomata are closed (Arve et al. 2011).

Plant develops an integrated mechanism to maintain 

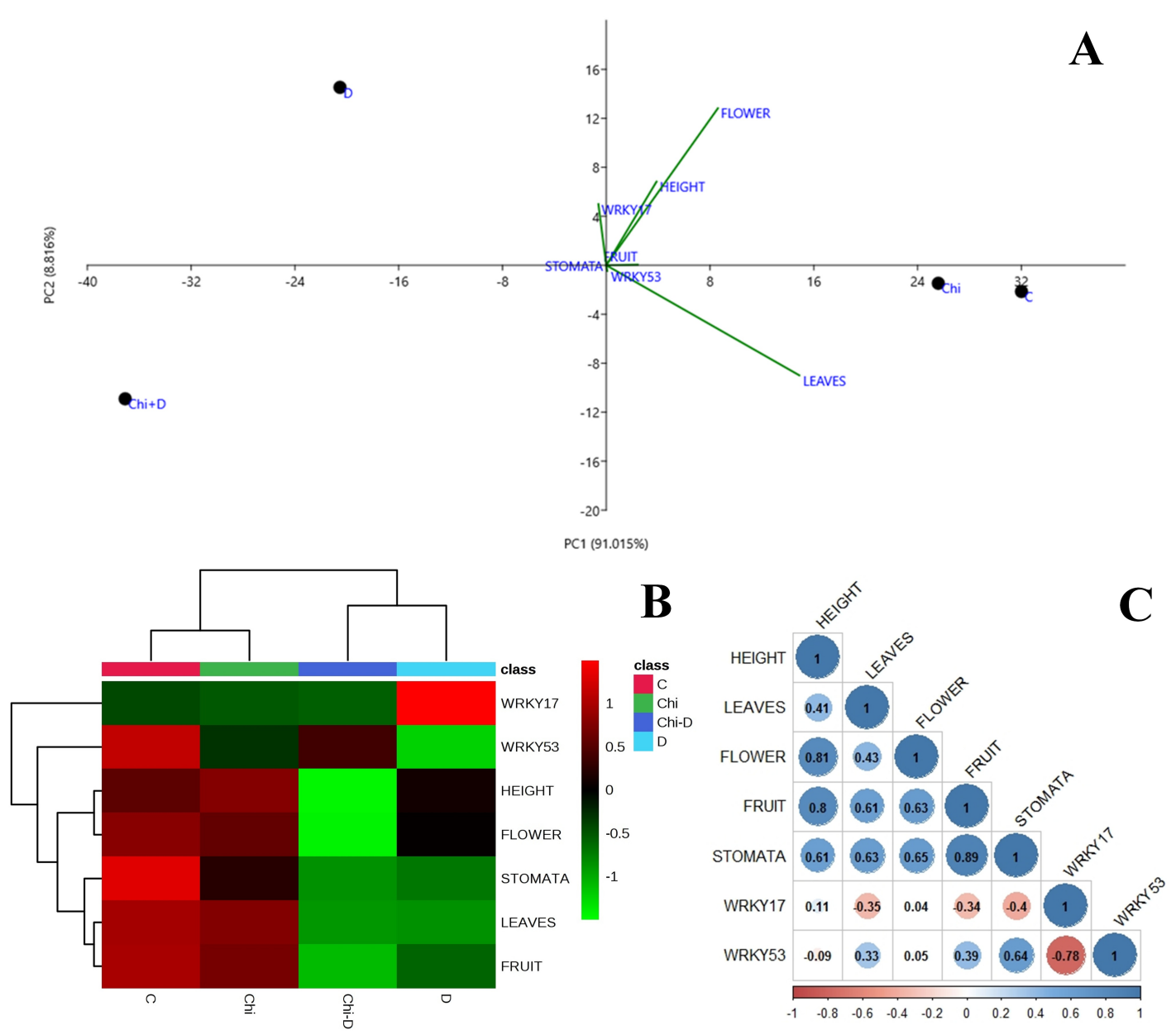

FIGURE 4 The correlation between physiological and molecular responses after chitosan and drought treatment combination in red chili plants including (A) score plot of the principal component-biplot analysis (PCA), the longer and the more clear the initial line, the stronger the certain parameters classify each treatment group, (B) the heatmap clustering analysis (HCA), the higher similarity score is defined by the red color, while the lower score is by the green, and (C) the correlation analysis, the positive correlation is defined by the blue color, while the negative correlation is by the red. HEIGHT, height increment; LEAVES, the number of leaves; FLOWER, the number of flowers; FRUIT, the number of fruit; STOMATA, the percentage of opened stomata; WRKY17, the expression level of WRKY17 gene; WRKY53, the expression level of WRKY53 gene. Chi, $1 \mathrm{mg} / \mathrm{mL}$ chitosan; Chi-D, $1 \mathrm{mg} / \mathrm{mL}$ chitosan and 50\% drought; D, 50\% drought; C, control.

its growth and survival under stress. Hence, the analysis of plant signaling molecules such as transcription factor WRKY will shed a light on how the mechanism is carried out. WRKY is a group of transcription factors characterized by the presence of one or two conserved WRKY domains on the N-terminus and a zinc finger motif on the C-terminus, involved in growth, development, and stress response regulation through ABA and ROS signaling mechanisms. For instance, WRKY41, WRKY70, and WRKY1 were reported involved in increasing drought stress tolerance in transgenic tobacco plants by regulating stomatal closure and ROS level. They also documented the wider opened stomata in the overexpressed $G h$ WRKY17 mutant line compared to wild type when treated with exogenous ABA (Yan et al. 2014). In addition, it was also documented that AtWRKY53 was thought to regulate opened stomata by increasing starch degradation for keeping stomatal opened. However, the opened stomata under drought stress conditions could promote water loss, resulting in plant dehydration. Therefore, the higher expression of WRKY17 and WRKY53 gene could decrease the plant's sensitivity against stress (Sun and Yu 2015).

The WRKY transcription factor was reported as a positive or negative regulator in many biological processes including, plant development, defense regulation, and stress response (Cai et al. 2017). The superior expression level of WRKY17 under stress conditions might decrease the sensitivity of ABA signaling. The decreased ABA sensitivity to guard cells and the lower ABA content is thought to play a role in increasing water loss and decreasing drought tolerance. Based on the previous study, during drought stress the expression of genes related to ROS degrading enzymes including catalase (CAT) and superoxide dismutase (SOD) decreases in GhWRKY17 transgenic plants group, while the expression of genes related to ROS (RbohA and $R b o h B$ ) production increases significantly compared to wild type plants. This causes an increase in ROS accumulation such as hydrogen peroxide $\left(\mathrm{H}_{2} \mathrm{O}_{2}\right)$ and anion dioxide $\left(\mathrm{O}^{2-}\right)$. Therefore, Gossypium hirsutum WRKY17 was thought to reduce the plant's tolerance to osmotic stress 
(Yan et al. 2014). Meanwhile, the role of Arabidopsis WRKY53 in the regulation of stomatal state during drought was thought to be not directly related to ABA signaling, this was characterized by the expression of genes related to ABA biosynthesis ( $A B A 1, A B A 2$, and $A B A 3$ ) and ABA levels that do not differ significantly either AtWRKY53 transgenic plants or control group. Based on the previous investigation, AtWRKY53 was suggested to regulate stomatal movement by increasing the degradation of starch to malate for keeping stomata open. In brief, an AtWRKY53 can directly bind to the QQS promoter sequence and then leads to an increase in starch metabolism (Sun and Yu 2015).

This study found that chitosan application under drought stress conditions might suppress the expression level of the WRKY17 gene compared to drought treatment. However, the lower expression level was also recorded in WRKY53 in all treatments. This finding suggested that both genes were involved in the stomatal opening regulation after the treatments. The previous study that characterized the functional analysis of WRKY17 genes in cotton and Arabidopsis sp. showed a similar result to the over expression of GhWRKY17 and AtWRKY53 which could also regulate the wider opened stomata (Yan et al. 2014; Sun and Yu 2015). As explained in the correlation analysis (Figure 4C), the lower expression level of the WRKY53 gene is positively correlated with the lower opened stomata $(r=0.64)$. Therefore, it is suggested that the regulation of the stomatal state under the treatments is influenced by the WRKY53 gene, leading to the growth alteration.

WRKY genes involve in ABA and ROS production, this is suggested that the lower percentage of opened stomata leading to lower plant growth after chitosan application under drought stress condition (Chi-D) might be influenced by the suppression of the WRKY17 and WRKY53 genes. In addition to impeded plant growth, the lower opened stomata also promote the plant's defense system through maintaining water capacity and/ or signal transduction (Yan et al. 2014). Under drought conditions, the plant's water capacity becomes more critical to maintain the plant's life, so that the water loss through stomata might need to be regulated. Thus, it is not surprising to find that stomata in the Chi-D group are only slightly opened. This further supports our suggestion that the intensive chitosan application could reduce the number of opened stomata, and more pronounced when combined with drought stress. The previous study indicated that the silencing of GhWRKY27a enhanced drought tolerance in cotton marked by less water loss, higher survival rate, and less $\mathrm{H}_{2} \mathrm{O}_{2}$ accumulation (Yan et al. 2015).

Although WRKY17 and WRKY53 in almost all treatments showed lower gene expression, the only WRKY17 in drought treatment was expressed 7-fold higher than control. This is supported by the previous study that WRKY17 in maize was up-regulated after $12 \mathrm{~h}$ of drought stress treatment (Cai et al. 2017). Although a low percentage of the opened stomata between Chi-D and D treatments is quite similar, the superior expression of WRKY17 in drought treatment (D) might associate with the plant's responses under drought stress conditions. This is suggested that $W R K Y 17$ has a specific role in response to drought stress. We also suggested that WRKY17 and WRKY53 have different roles in plant defense mechanisms after chitosan application and drought treatment. This is supported by the statistical analysis that showed a negative correlation ( $r=$ -0.78 ) between the genes. A more comprehensive analysis of WRKY17 and WRKY53 is crucial in developing strategies to define the plant's molecular response to drought. The determination of WRKY17 and WRKY53 target genes will allow us to manipulate plants response under drought stress.

\section{Conclusions}

The double treatment of $1 \mathrm{mg} / \mathrm{mL}$ chitosan application and 50\% drought stress (Chi-D) in red chili plants significantly decreased plant growth performance, including the height increment, followed by the decrease in the number of leaves, flower, and fruit. The percentage of opened stomata on chitosan-drought treatment significantly decreased by up to $30.67 \%$ and followed by the decrease in WRKY17 and WRKY53 genes expression level. Therefore, chitosan application was suggested could not alleviate plants grown under drought stress, but enhance plant's resistance against drought stress. However, WRKY17 expression level on drought treatment was significantly upregulated up to 7-fold higher than control. Furthermore, we suggested that WRKY17 has a specific role in response to drought stress.

\section{Acknowledgments}

This research was funded by "Penelitian Strategis Nasional Institusi - 2017”, The Ministry of Research, Technology, and Higher Education - Indonesia. Chili pepper seed cultivar LADO was obtained from East-West Seed Indonesia Ltd. (PT. Ewindo). Thanks to Dr. Turhadi, M.Si who helped in data analysis.

\section{Authors' contributions}

MAA and HHC carried out the laboratory study. RRE, MAA, and FMD designed the study. MAA and KM analyzed data. All authors wrote and read the manuscript.

\section{Competing interests}

The authors declare no competing interest.

\section{References}

Arve LE, Torre S, Olsen JE, Tanino KK. 2011. Stomatal Responses to Drought Stress and Air Humidity. In: A Shanker, B Venkateswarlu, editors, Abi- 
otic Stress in Plants, chapter 12. Rijeka: IntechOpen. doi:10.5772/24661.

Cai R, Dai W, Zhang C, Wang Y, Wu M, Zhao Y, Ma Q, Xiang Y, Cheng B. 2017. The maize WRKY transcription factor ZmWRKY17 negatively regulates salt stress tolerance in transgenic Arabidopsis plants. Planta. 246(6):1215-1231. doi:10.1007/s00425-0172766-9.

Dorji K, Behboudian MH, Zegbe-Domínguez JA. 2005. Water relations, growth, yield, and fruit quality of hot pepper under deficit irrigation and partial rootzone drying. Sci Hortic. 104(2):137-149. doi:10.1016/j.scienta.2004.08.015.

Duriat A, Gunaeni N, Wulandari A. 2007. Penyakit Penting Tanaman Cabai dan Pengendaliannya. Bandung: BALITSA.

Dzung NA, Khanh VTP, Dzung TT. 2011. Research on impact of chitosan oligomers on biophysical characteristics, growth, development and drought resistance of coffee. Carbohydr Polym. 84(2):751-755. doi:10.1016/j.carbpol.2010.07.066.

Esyanti RR, Dwivany FM, Mahani S, Nugrahapraja H, Meitha K. 2019. Foliar application of chitosan enhances growth and modulates expression of defense genes in chilli pepper (Capsicum annuum L.). Aust J Crop Sci. 13(1):55-60. doi:10.21475/ajcs.19.13.01.p1169.

Fibriyanti A. 2008. Pengaruh filter cahaya dan media tanam terhadap pertumbuhan dan kualitas penampilan tanaman. Ph.D. thesis, Institut Pertanian Bogor, Bogor.

Him TR, Radhouane L. 2015. Growth and yield responses of two Tunisian pepper (Capsicum annuum L.) varieties to salinity and drought stress. Int J Sci. 14(2):159-167.

Iriti M, Picchi V, Rossoni M, Gomarasca S, Ludwig N, Gargano M, Faoro F. 2009. Chitosan antitranspirant activity is due to abscisic acid-dependent stomatal closure. Environ Exp Bot. 66(3):493-500. doi:10.1016/j.envexpbot.2009.01.004.

KEMENTAN. 2015. Statistik Produksi Hortikultura Tahun 2014. Kementerian Pertanian Direktorat Jenderal Hortikultura.

KEMENTAN. 2016. Outlook Komoditas Pertanian Sub Sektor Hortikultura : Cabai. Jakarta: Pusat Data dan Sistem Informasi Pertanian Sekretariat Jenderal Kementerian Pertanian Tahun 2016.

Khan AL, Shin JH, Jung HY, Lee IJ. 2014. Regulations of capsaicin synthesis in Capsicum annuum L. by Penicillium resedanum LK6 during drought conditions. Sci Hortic. 175:167-173. doi:10.1016/j.scienta.2014.06.008.

Livak KJ, Schmittgen TD. 2001. Analysis of relative gene expression data using real-time quantitative PCR and the 2- ${ }^{\Delta \Delta C}$ T method. Methods. 25(4):402-408.

Malekpoor F, Pirbalouti AG, Salimi A. 2016. Effect of foliar application of chitosan on morphological and physiological characteristics of basil un- der reduced irrigation. Res Crop. 17(2):354-359. doi:10.5958/2348-7542.2016.00060.7.

Mondal MM, Puteh AB, Dafader NC, Rafii MY, Malek MA. 2013. Foliar application of chitosan improves growth and yield in maize. J Food, Agric Environ. 11(2):520-523.

Ohta K, Morishita S, Suda K, Kobayashi N, T H. 2004. Effects of chitosan soil mixture treatment in the seedling stage on the growth and flowering of several ornamental plants. J Hortic Sci. 73(1):66-68. doi:10.2503/jjshs.73.66.

Pichyangkura R, Chadchawan S. 2015. Biostimulant activity of chitosan in horticulture. Sci Hortic. 196:4965. doi:10.1016/j.scienta.2015.09.031.

Salachna P, Zawadzińska A. 2014. Effect of chitosan on plant growth, flowering and corms yield of potted freesia. Ecol Eng. 15(3):97-102. doi:10.12911/22998993.1110223.

Showemimo, Olarewaju. 2007. Drought Tolerance Indices in Sweet Pepper (Capsicum annuum L.). Int J Plant Breed Genet. 1:29-33. doi:10.3923/ijpbg.2007.29.33.

Sumarni N, Muharam A. 2005. Budidaya Tanaman Cabai Merah. Bandung: BALITSA.

Sun Y, Yu D. 2015. Activated expression of AtWRKY53 negatively regulates drought tolerance by mediating stomatal movement. Plant Cell Rep. 34(8):12951306. doi:10.1007/s00299-015-1787-8.

Sung Y, Chang YY, Ting NL. 2005. Capsaicin biosynthesis in water-stressed hot pepper fruits. Bot Bull Acad Sin. 46(1):35-42. doi:10.7016/BBAS.200501.0035.

Taylor JE, Whitelaw CA. 2001. Signals in abscission. New Phytol. 151(2):323-339. doi:10.1046/j.0028646x.2001.00194.x.

Wasternack C. 2014. Action of jasmonates in plant stress responses and development - Applied aspects. Biotechnol Adv. 32(1):31-39. doi:10.1016/j.biotechadv.2013.09.009.

Yan H, Jia H, Chen X, Hao L, An H, Guo X. 2014. The cotton WRKY transcription factor GhWRKY17 functions in drought and salt stress in transgenic Nicotiana benthamiana through aba signaling and the modulation of reactive oxygen species production. Plant Cell Physiol. 55(12):2060-2076. doi:10.1093/pcp/pcu133.

Yan Y, Jia H, Wang F, Wang C, Liu S, Guo X. 2015. Overexpression of GhWRKY27a reduces tolerance to drought stress and resistance to Rhizoctonia solani infection in transgenic Nicotiana benthamiana. Front Physiol. 6(SEP):1-16. doi:10.3389/fphys.2015.00265. 